\title{
Effects of holistic grazing management on milk production, weight gain, and visitation to grazing areas by livestock and wildlife in Laikipia County, Kenya
}

\author{
Priscilla K. Lalampaa ${ }^{1 *}$, Oliver V. Wasonga ${ }^{1}$, Daniel I. Rubenstein ${ }^{2}$ and Jesse T. Njoka ${ }^{1}$
}

\begin{abstract}
Background: Grazing is an important management tool for maintaining healthy ecosystems and improving rangelands productivity. However, its effectiveness for this purpose is dependent on timing and frequency of grazing, as well as the type of animal. Understanding the effects of grazing management on rangeland ecosystems is critical in ensuring sustainable use of grazing resources and enhanced livestock production. This study assessed the effects of holistic grazing on animal productivity and range use pattern in Laikipia County of Kenya.

Results: The results revealed that the average milk yields (106 \pm 20.1$)$ of animals in holistic grazing areas (HGA) were significantly $(p<0.05)$ higher than those in traditional grazing areas (TGA) $(101 \pm 20.1)$. Weight gain of animals in HGA was significantly $(0.13 \pm 0.01)$ higher as compared to those in TGA $(0.07 \pm 0.01)$. The number of livestock grazing was significantly $(p<0.05)$ higher in HGA $(74 \pm 10 \%)$ than those in TGA $(57 \pm 10 \%)$. In addition, the number of wild life grazing was significantly $(p<0.05)$ higher in HGA $(74 \pm 18 \%)$ than in TGA $(32 \pm 18 \%)$.
\end{abstract}

Conclusions: The results indicate that holistic grazing management has the potential to improve animal performance, as well as condition of range areas as evident in the preference shown by frequent visits to HGA by both livestock and wildlife.

Keywords: Camera traps, Continuous grazing, Animal performance, Rest periods, Wildlife visits

\section{Introduction}

In Kenya, rangelands cover over $80 \%$ of the land surface. They are mainly utilized for livestock production and wildlife conservation (Ottichilo et al. 2000; Odadi et al. 2011) and support livelihoods of many rural communities (Eriksen and Watson 2009). However, their productivity and sustainability is threatened by unsustainable land-use systems that perpetuate among them causes of rangeland degradation. Overgrazing, mainly attributed to restricted herd mobility due to conversion of rangelands to other land uses, leads to reduction of palatable herbaceous plant species and increase of the unpalatable ones (Smet and Ward 2006) that constitutes a form of range degradation. It also affects the soil quality (Snyman

\footnotetext{
* Correspondence: priscilla.lalampaa@yahoo.com

${ }^{1}$ Faculty of Agriculture, Department of Land Resource Management and Agricultural Technology, University of Nairobi, P.O. Box 29053-00625, Nairobi, Kenya

Full list of author information is available at the end of the article
}

and Du Preez 2005; Elmore and Asner 2006), herbaceous plant species composition (Tefera et al. 2007), and woody vegetation cover. Palatable species decline as grazing pressure increases and are replaced by shrubs or other vegetation which are less preferred by livestock and more resistant to grazing (Thurow et al. 1986; Dyksterhuis 1949). Pastoralism offers a viable production system that enables rangelands to be used productively ( Galvin 2009) because it allows mobility which enhances pastoralist adaptation to spatial and temporal variations in rainfall and grazing resources. In drought years, many communities make use of fall-back grazing areas unused in "normal" dry seasons because of distance, land tenure constraints, animal disease problems, or conflict (Blench and Sommer 1999). It is therefore imperative to maintain and improve sustainable production of pastoral communities (Brooks et al. 2009) by identifying and implementing suitable grazing management strategies that enhance rangeland productivity. Holistic 
grazing management (HGM) is one of the grazing management regimes that have been adopted in some of the rangeland ecosystems. It tackles bringing back bare grounds and increases the productivity of grasslands (Savory and Butterfield 1999). HGM involves high-intensity grazing for short duration coupled with rest periods. Practitioners who support HGM argue that when animals are concentrated in small areas for short periods of time, the effect breaks the ground, allowing for water and nutrient flow, while sowing seeds and adding fertilizer through dung and urine (Strauch et al. 2009; Savory 1983). This, coupled with the rotation of the concentrated herd, ensures that plants regenerate, making the rangeland healthier and more productive (Abel and Blaikie 1989; Savory 1978). HGM differs from the traditional rotational grazing in that, with the latter, animals are not moved on the basis of plant responses, but the grazing periods set aside for each paddock (Jacobo 2006; Wolf 2011). The movement of animals is more flexible in HGM depending on the prevailing weather conditions, plant growth, or the changing animal needs (Wolf 2011). In traditional grazing, animals are grazed on the same piece of land for a very long period of time. The plants are overgrazed hence do not have adequate time for recovery leading to the loss of vigor resulting in declining productivity (Kioko et al. 2012; Jacobo 2006). It is known to reduce stress on vegetation by controlling the amount of time the animals are on and off the land. The optimal number, size of paddocks, stocking density, and length of grazing and recovery periods vary widely with site, time, and management objectives (Barnes et al. 2008). HGM has been practiced in several private group ranches in Zimbabwe (Abel and Blaikie 1989), in the USA (Strauch et al. 2009), and South Africa, Botswana, and Namibia (Oba et al. 2001) and is mostly used as emerging means of restoring degraded rangelands. Northern Rangeland Trust in Kenya has been spearheading promoting and adoption of the holistic grazing system in many parts of the Laikipia County (Ritchie et al. 2012). Various community ranches have adopted it; however, its adoption in pastoral production systems has been slow due to lean empirical evidence. There is limited information on its effects on animal productivity as well as wildlife visits to grazing areas. It is therefore paramount to assess its performance to guide on its implementation, adoption, and outscaling to other pastoral areas.

\section{Methods}

\section{Study area}

The study was conducted in Ilmotiok and Koija group ranches in Laikipia County of Kenya, which is situated between longitudes $36^{\circ} 5^{\prime}$ and $37^{\circ} 55^{\prime}$ East and latitudes $1^{\circ} 10^{\prime}$ and $3^{\circ} 10^{\prime}$ South (Fig. 1). The two sites are under Naibung'a conservancy which is made up of a total of nine group ranches, namely Tietmut, Kijabe, and Koija, Ilmotiok, Musul, Ilkilorit, Moropusi, ll-polei, and Munishoi. Laikipia County is situated on the equator on the leeward side of Mt Kenya and covers $9666 \mathrm{~km}^{2}$.

\section{Climate, landforms, and soils}

Rainfall in Laikipia County is highly variable both in space and time with an annual range of $400-800 \mathrm{~mm}$. The long rains occur between March and May, while short rains fall in October to November (Odadi 2010). Mean monthly maximum temperature range from 25 to $30{ }^{\circ} \mathrm{C}$, while minimum temperature ranges from 12 to $17{ }^{\circ} \mathrm{C}$ with July and August being the coldest and windiest months (Odadi 2010)

Laikipia County consists mainly of plateau bounded by the great rift valley to the west and the Aberdare ranges and Mt. Kenya ridges to the south. The plateau descends towards the floor of rift valley in the northwest, while in the north and east it falls into areas that extend over hundreds of kilometers towards the north.

There are two main soil types in Laikipia County: red soils (oxisols) and black cotton soils (vertisols).On the eastern part of the County, there are mainly sandy and well-drained red soils on steep slopes and areas of high elevation. Black cotton soils characterized by impeded drainage, high clay content, and high levels of calcium carbonate are mainly found in the Laikipia plateau on western part of the County. Ilmotiok and Koija group ranches are dominated by red soils with black cotton soils found in some areas.

\section{Flora and fauna}

Vegetation in the study area is largely classified as wooded grasslands comprising of Themenda-pennisetum grassland, Acacia bushland, and leafy bushlands. Acacia brevispica dominates the open thickets, while Acacia mellifera and Acacia nilotica mainly occur in arid zones. Acacia bushlands are commonly found on the well-drained red soils in the AEZ VI (Odadi 2010).

Laikipia County hosts one of the largest wildlife populations in Kenya (Heath 2000). The current aerial count estimates in the area put biomass density of large wild herbivores excluding elephants at 0.83 tons $\mathrm{km}$ ${ }^{-2}$ (Georgiadis et al. 2007). Cattle are the dominant livestock comprising $85 \%$ of total livestock biomass density in the County (Georgiadis et al. 2007). Other livestock species in the study site include sheep, goats, camels, and donkeys.

\section{Study design}

Study sites in Ilmotiok and Koija group ranches were selected to represent the holistic grazing management and traditional grazing regime, respectively. Unlike Ilmotiok group ranch where holistic grazing management was 


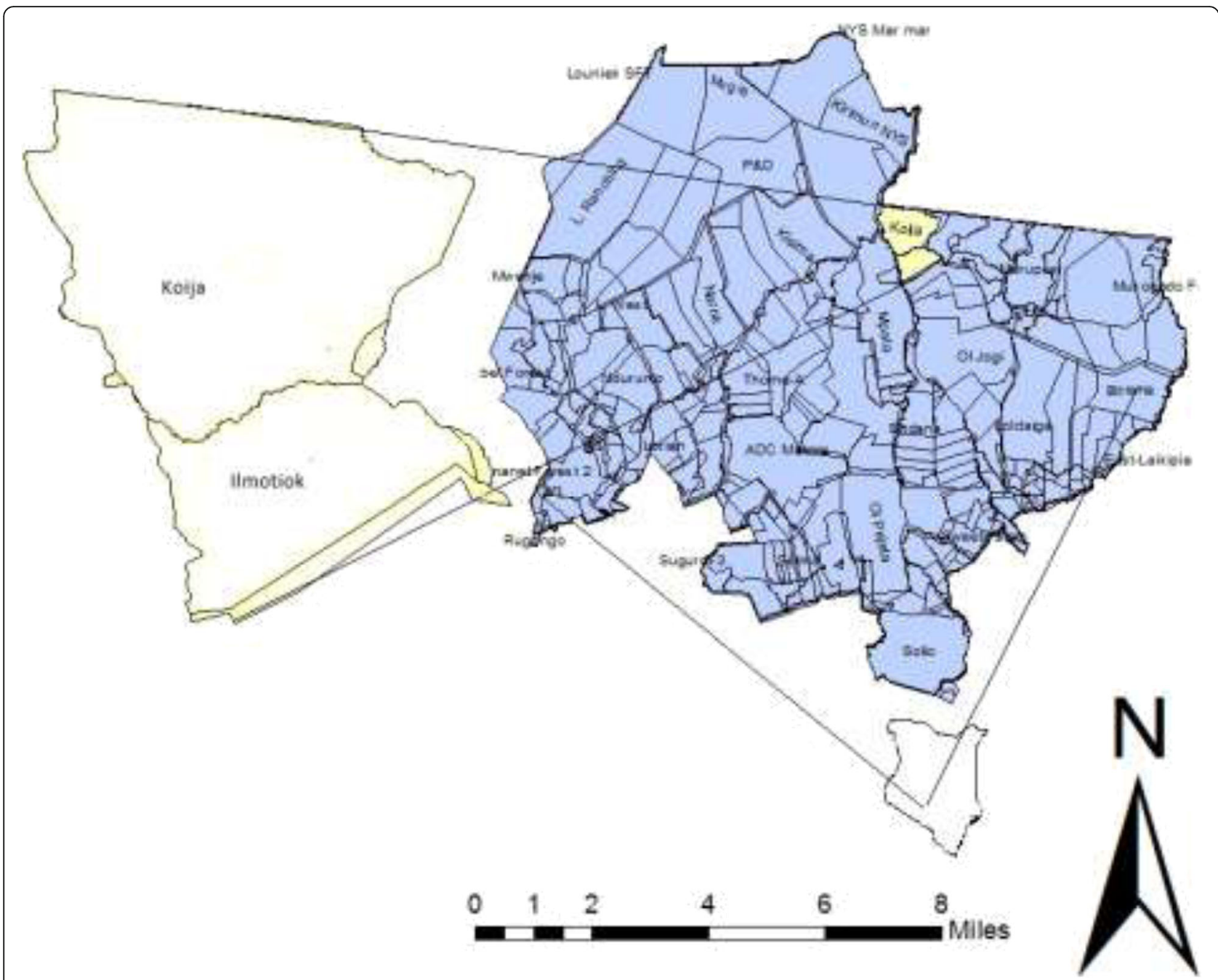

Fig. 1 Study area (Koija and IImotiok group ranches)

being implemented, study sites in Koija had been under continuously grazing throughout the year.

The study sites were selected on the basis of grazing history and had similar soil types and landforms. Holistic grazing areas (HGA) represented areas in which highintensity grazing, short-duration grazing alternated with rest period had been practiced for 2 years prior to time of the study, while traditional grazing areas (TGA), which were used as controls were sites where continuously grazing had been practiced throughout the year. A total of eight experimental plots measuring $25 \mathrm{~m}$ by $25 \mathrm{~m}$ were established in the study area, four in each of the two sites.

\section{Data collection and analysis}

\section{Measurements of goat and sheep weight gain and goat} milk yield

Six herds were chosen from the households in the study area, three each in HGA and TGA. In each herd, four 1- year-old small East African goats weighing between 22 and $23 \mathrm{~kg}$ and red Maasai sheep of male sex with comparable weighing 28 and $29 \mathrm{~kg}$ were chosen for the experiments. Two of the selected animals were fitted with collar GPS devices (Fig. 2) to track their movements and determine distances traveled and proportion of time spent in HGA and TGA. The collars also enabled us to know whether the experimental animals grazed in our plots. The GPS data was downloaded and used to determine distance covered when grazing and proportion of time spent grazing and to generate animal movement tracks.

In addition, two small East African goats in the mid lactation stage were selected in each herd for milk yield measurements. Each of the selected goats had given birth three times and had aged between 3 years.

Body weight measurements of the experimental animals were done before the experiment and thereafter at a week interval for a period of 4 months using an 


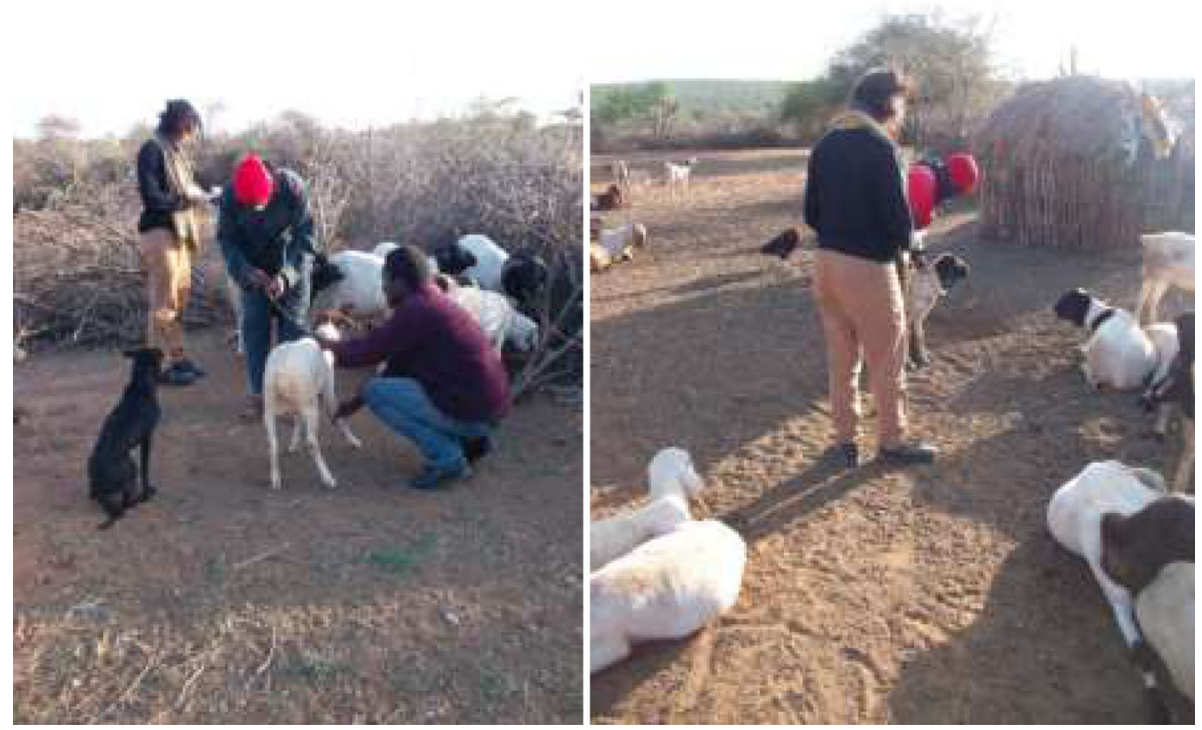

Fig. 2 Livestock being fitted with GPS devices

electronic portable weighing scale. The measurements were done during both the wet and dry seasons. Weight measurements were routinely carried out at 7 am and 8 am after overnight starvation to ensure that undigested materials do not introduce biases in the estimates. Average daily weight gain for individual animals was calculated using the following formula:

$$
\text { Average daily weight gain }=\left(\frac{\text { Weight gain in } \mathrm{kg}}{\text { Number of days }}\right)
$$$$
\text { Distance travelled }=\frac{\text { Total distance travelled in } \mathrm{km}}{\text { Number of days }}
$$

Proportion of time spent (\%)

$$
=\left(\frac{\text { Number of hours spent in a grazing area }}{\text { Total time spent outside the homestead in hours }}\right) \times 100
$$

Milk yield measurements from goats were taken every day in the morning for a period of four months during dry and wet seasons. Average daily milk yield were computed using the following formula;

$$
\text { Average milk production }=\frac{\text { Total amount of milk in } \mathrm{ml}}{\text { Number of days }}
$$

\section{Estimation of frequency of animal visits to holistic and traditional grazing areas}

Plots measuring $25 \mathrm{~m}$ by $25 \mathrm{~m}$ were established in the study area, four each within HGA and TGA. Eight infrared digital scouting cameras traps were placed in all eight plots and set to take three pictures every $9 \mathrm{~s}$ for $24 \mathrm{~h}$ a day. The cameras were placed strategically on the corner of each plot on pole or tree at the height of about $3 \mathrm{~m}$ above the ground to enable it take pictures of the whole plot.

The number of animals visiting HGA and TGA was estimated from counts of the photos taken by the installed cameras. From the pictures, it was possible to determine whether the animals were grazing or just walking through the plots. The number of animals grazing and walking in both HGA and TGA during wet and dry seasons was computed using the following formula:

Percent animals grazing $=\left(\frac{\text { Number of animals grazing }}{\text { Total number of animals }}\right) \times 100$

Percent animals walking $=\left(\frac{\text { Number of animals walking }}{\text { Total number of animals }}\right) \times 100$

The collected data was analyzed using GenSTAT statistical software. $T$ test was used to determine if there was significant difference in livestock milk yield, weight gain, and frequency of visits by wildlife and livestock between HGA and TGA. Fisher's protected LSD test was used to separate the treatment means.

\section{Results}

\section{Goat milk yield and sheep and goat weight gains}

Average daily milk yield from goats that accessed HGA was significantly $(p<0.05)$ higher than those in TGA (Fig. 3). Seasonal variation in milk yield was not significant.

Goats and sheep in HGA had significantly $(p<0.05)$ higher daily weight gain than those that accessed TGA (Fig. 3). Significantly $(p<0.05)$ higher daily weight gain 


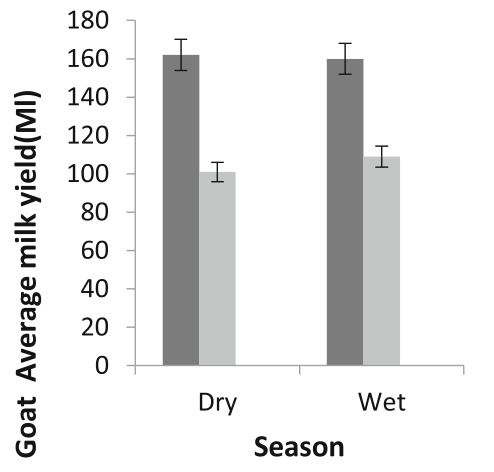

a)

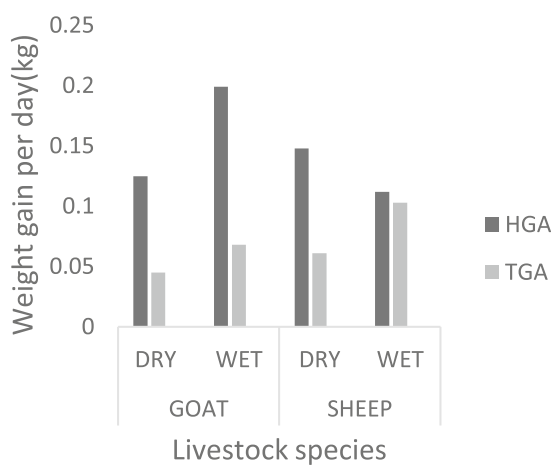

b)

Fig. 3 Goat milk yield (a) and weight gain of sheep and goats (b) during wet and dry seasons

was observed during the wet season than in the dry season in both HGA and TGA. The observed increase was however higher in HGA than in TGA (Fig. 3).

Average daily weight gain was significantly $(p<0.05)$ higher in sheep grazed in HGA as compared to those in TGA (Fig. 3). Significant $(p<0.05)$ seasonal variations was observed with weight gain in the dry season being higher than in the wet season in HGA.

Time spent and distance traveled by goats and sheep in holistic and traditional grazing areas

Distance traveled, time spent, and livestock movement tracks in holistic and traditional grazing areas are presented in Figs. 4, 5, 6, and 7, respectively.

Herds chosen from HGA were found to spend significantly $(p<0.05)$ more time in HGA as compared to those from TGA. Seasonal variations were observed with herds from HGA and TGA spending significantly $(p<0.05)$ more time in HGA during the wet season than in the dry season. Goats and sheep traveled significantly $(p<0.05)$ shorter distance daily in HGA than in TGA. In addition, distance traveled daily by both goats and sheep was significantly ( $p$ $<0.05)$ shorter in the wet season than in the dry season.

Grazing movement patterns of goats were scattered (Fig. 5a), while movement of sheep were concentrated (Fig. 5c). Sheep and goat movement in HGA were cyclic and concentrated, while in TGA, movements were scattered (Fig. 5b, d).

During the dry season, the tracks in HGA were cyclic and linear (Fig. 6). On the other hand in TGA, the tracks were cyclic too but seem to spread outside the concentrated areas around the boma (Fig. 6). During the wet season, movement patterns in HGA were concentrated (Fig. 7) while in TGA, they were spread out though not like in the dry season (Fig. 7).

Frequency of livestock and wildlife visits to grazing patches Tables 1 and 2 present frequency of livestock and wildlife visits, respectively, in HGA and TGA.

The total number of livestock visits was significantly $(p<0.05)$ higher in HGA than in TGA and lower in the wet season both in HGA and TGA. Significant $(p<0.05)$

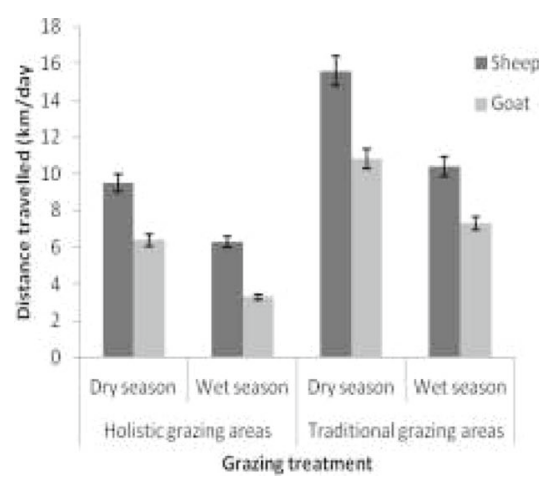

a) Distance travelled

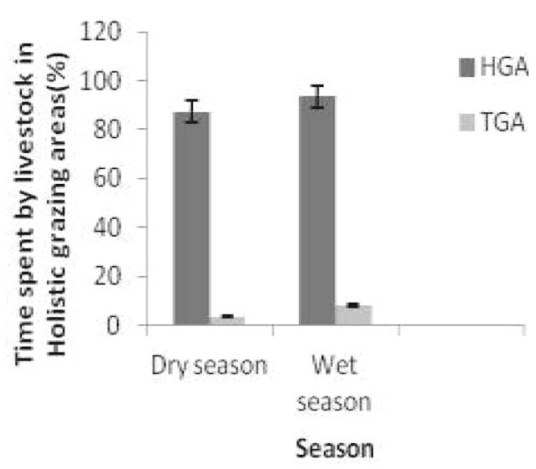

b) Time spent

Fig. 4 Distance traveled (a) and time spent (b) by sheep and goats in holistic and traditional grazing areas 


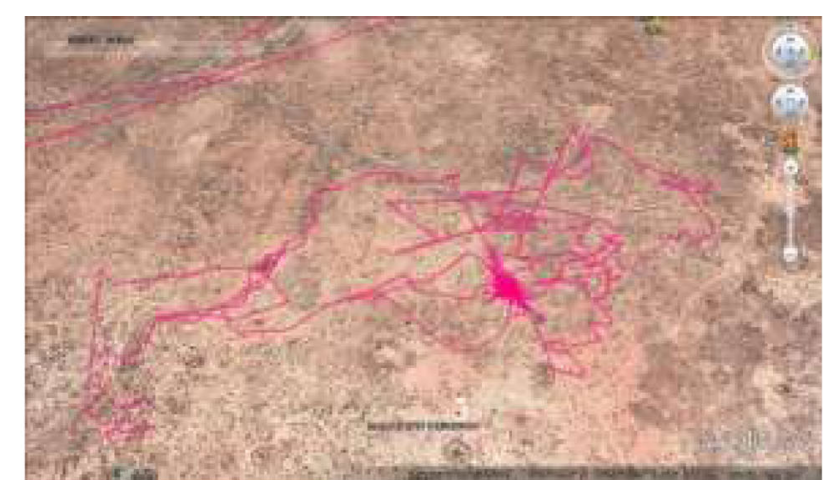

a) Goats in HGA

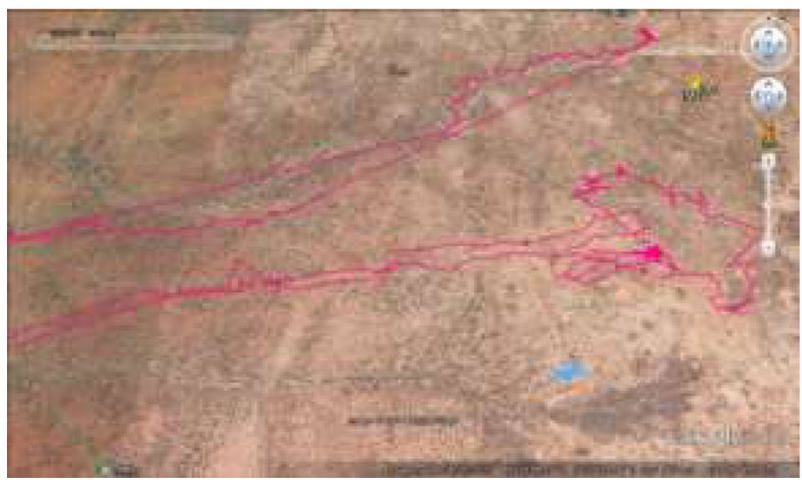

c) Goats in TGA

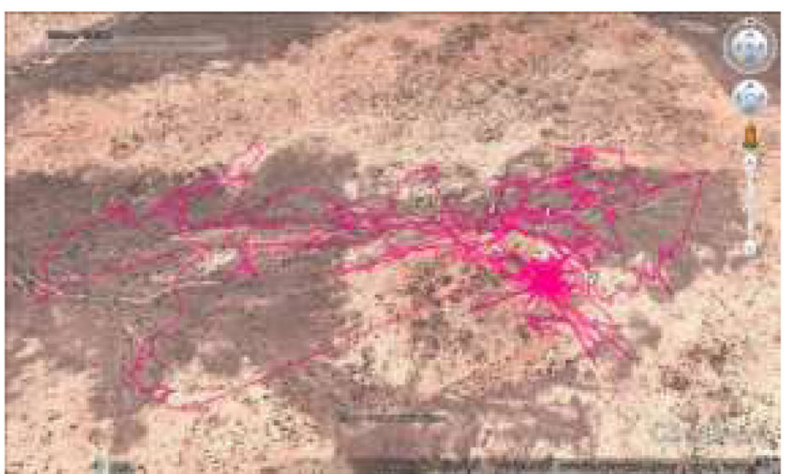

b) Sheep in HGA

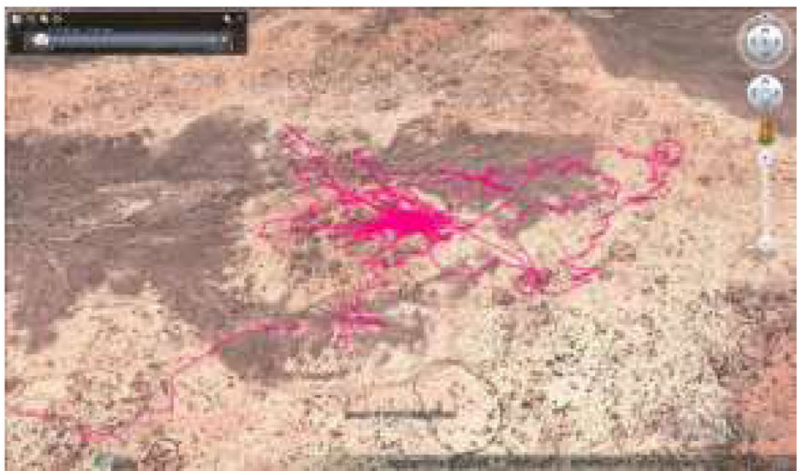

d) Sheep in TGA

Fig. 5 Goats and sheep grazing movement tracks in holistic and traditional grazing areas (a-d)

number of livestock was found grazing in HGA as compared to TGA. The number of livestock walking in TGA was significantly $(p<0.05)$ higher than in HGA and lower during the wet season both in HGA and TGA. HGA had significantly $(p<0.05)$ higher frequency of wildlife visits as compared to TGA. The number of wildlife grazing was significantly $(p<0.05)$ higher in HGA than in TGA. The proportion of wildlife walking was significantly $(p<0.05)$ higher in TGA as compared to HGA.

Frequency of wildlife visits was lower during the wet season than during the dry season and so was the frequency of wildlife grazing during the wet season as compared to the dry season in both HGA and TGA.

The wildlife species that frequently visited the two areas under study included elephants, zebras, and impalas. The number of these species was significantly $(p<0.05)$ higher in HGA than in TGA (Fig. 8). The number of zebras was high as compared to other wildlife both in HGA and TGA (Fig. 8). Impalas visited the areas mostly in the evening in the absence of livestock herd. Elephant and zebra visits both during the day and night were significantly lower during the wet season than in the dry season both in HGA and TGA.

\section{Discussion}

\section{Livestock milk yield and weight gain}

Goats and sheep in HGA had higher average daily weight gains than those in TGA. In addition, goats in HGA had higher average milk yield as compared to those in TGA. Such a difference may have been as a result of expected better forage quality and quantity in HGA due to adequate rest periods between grazing seasons and even distribution of excreta which improves water and nutrient cycling and favors establishment of desirable plant species (Hart et al. 1993; Todd-Brown et al. 2014). The distribution of excreta increases soil organic matter and nutrient content resulting in more fertile soils (Peterson and Gerrish 1995; Redden 2014) that provide good condition for plant growth leading to increased range productivity.

Low average daily livestock weight gain and milk yield in TGA could be due to continuous grazing that leads to heavy use of preferred plants and patches while avoiding others (Willms et al. 1988; O'connor 1992; Ash and Stafford-Smith 1996; Bailey et al. 1996; Gerrish 2004; Witten et al. 2005; Teague et al. 2011). Due to high grazing pressure, the density of highly preferred and palatable plants is reduced (Brand and Goetz 1986; 


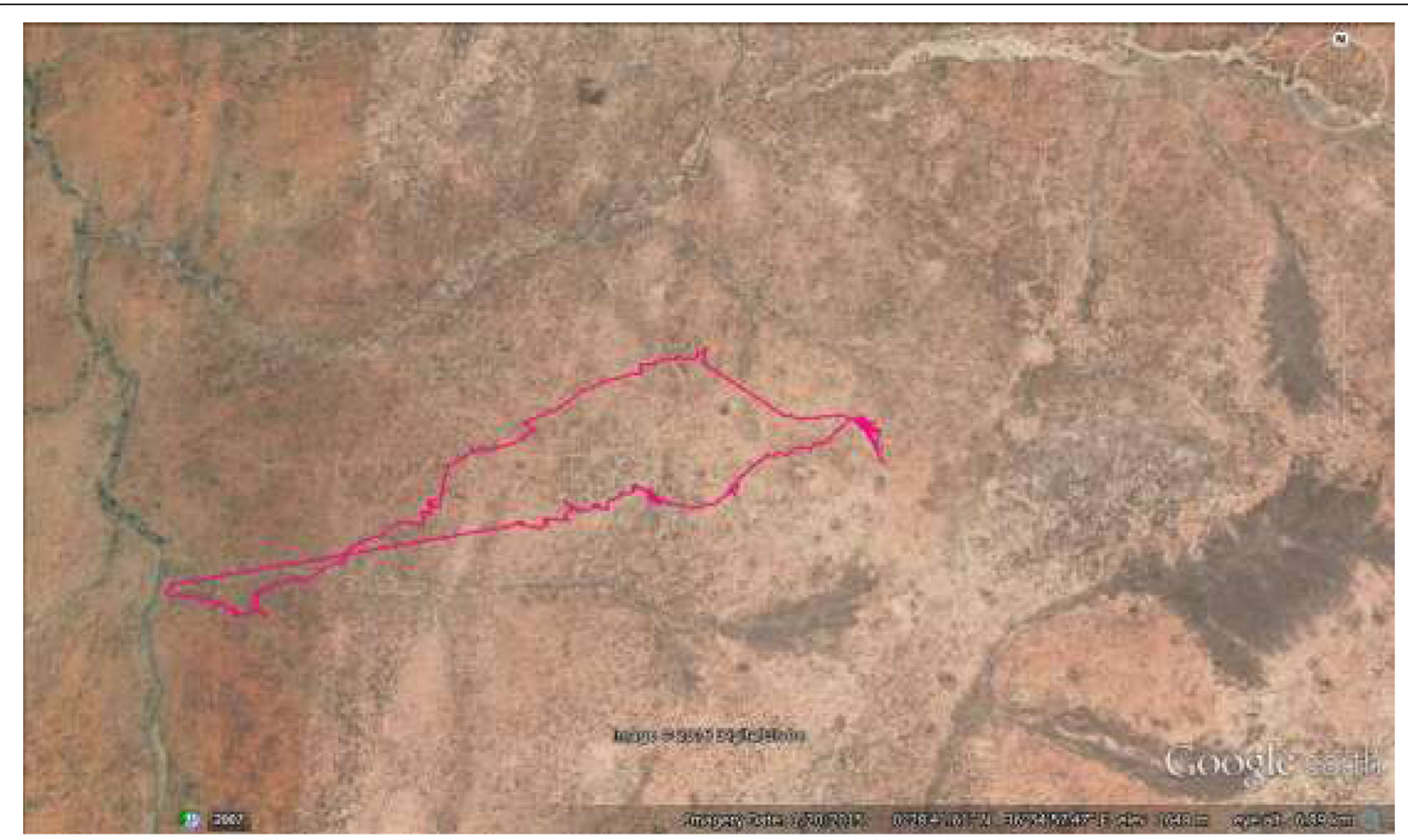

a) Movement in HGA

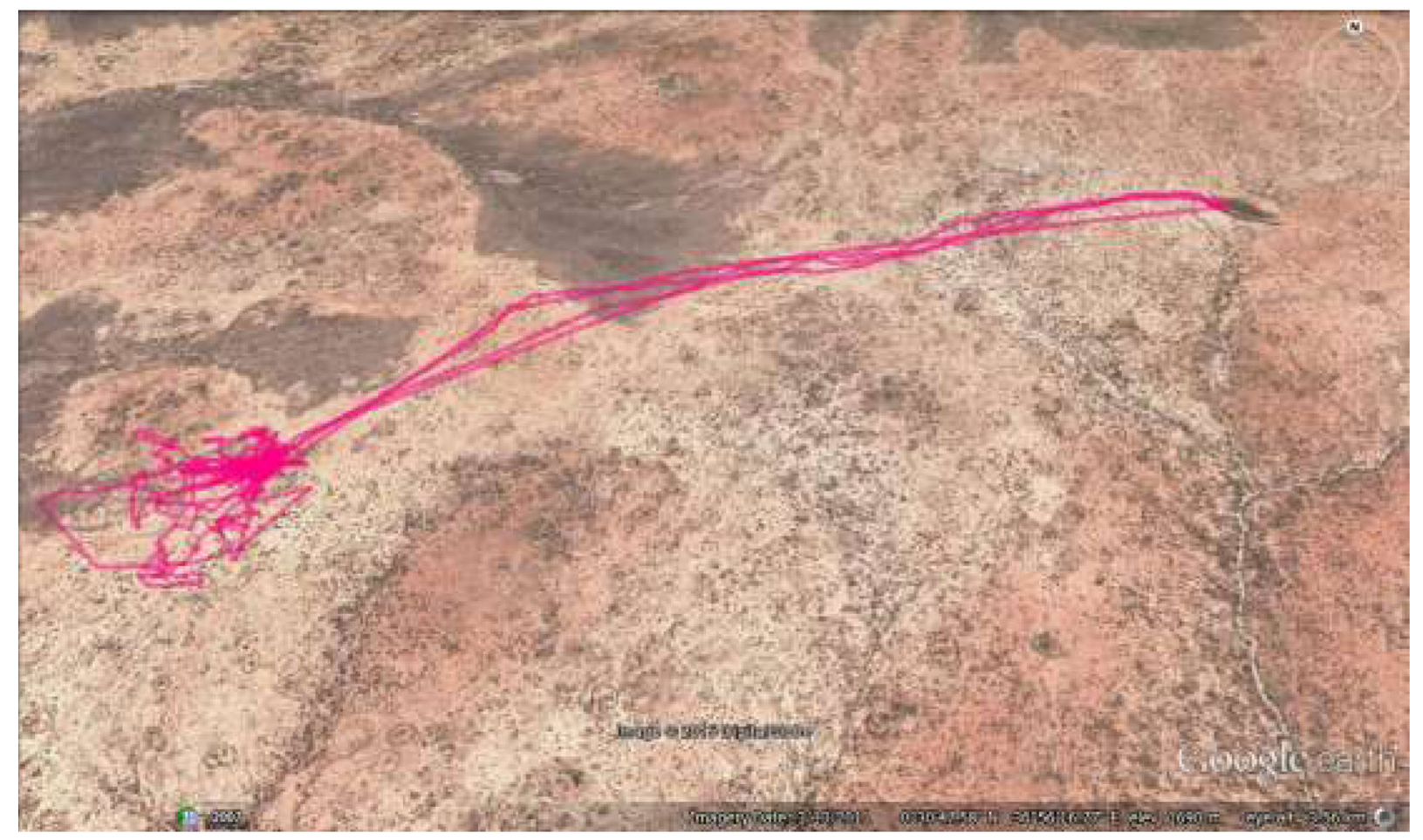

b) Movement in TGA

Fig. 6 Livestock grazing movement tracks in HGA (a) and TGA (b) during dry seasons 


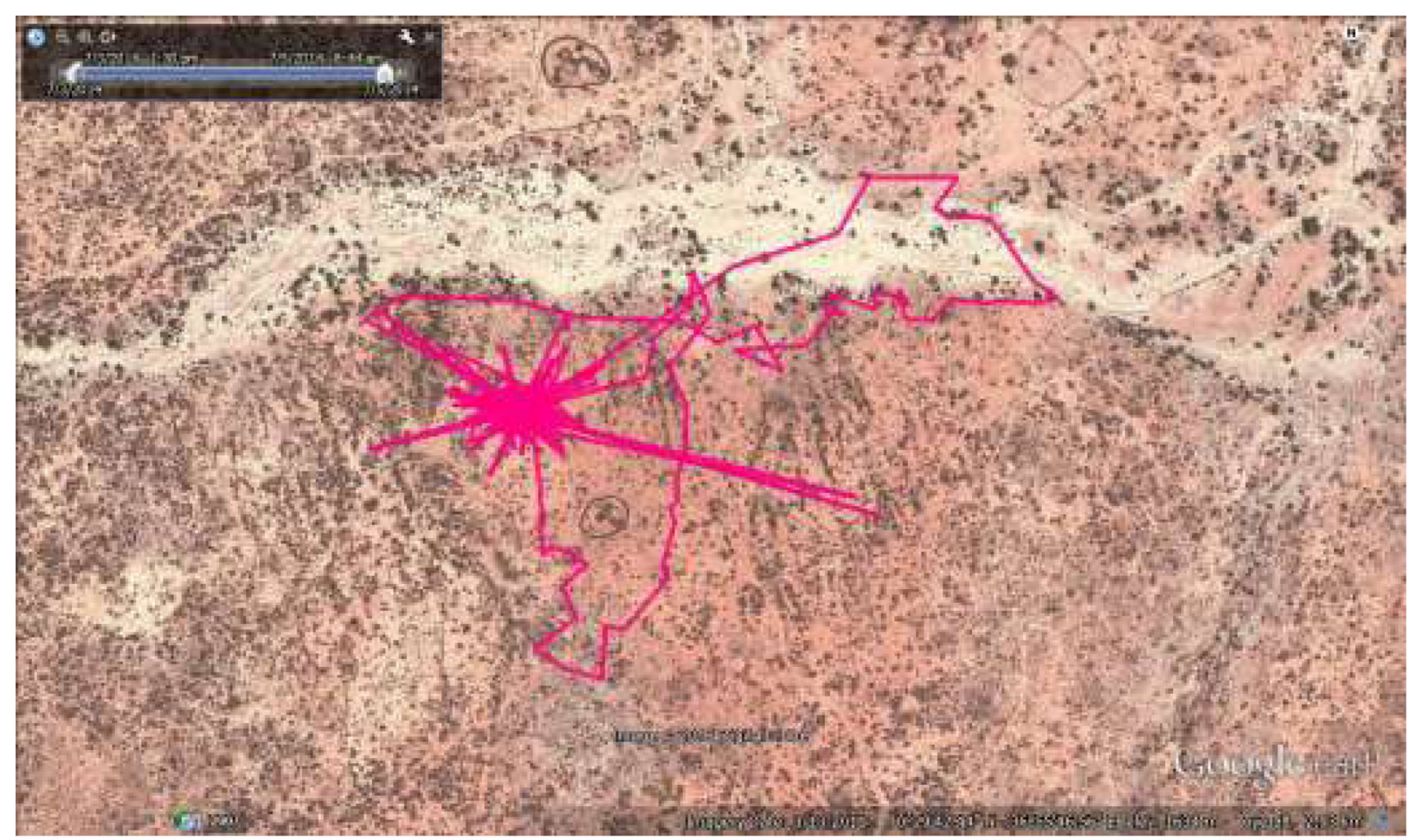

a) Movement in HGA

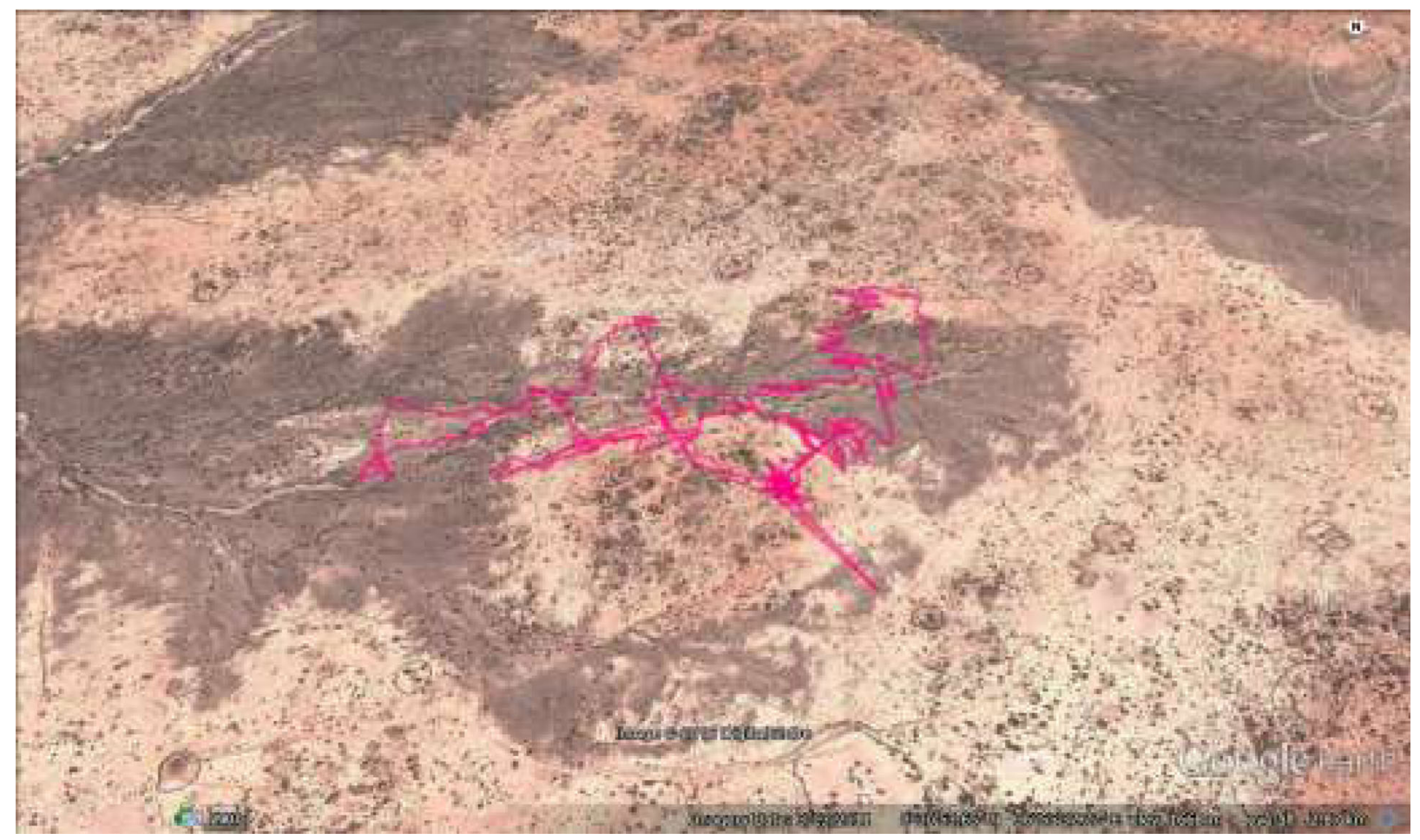

b) Movement in TGA

Fig. 7 Livestock grazing movement patterns in HGA (a) and TGA (b) during wet seasons 
Table 1 Frequency of livestock visits in holistic and traditional grazing areas

\begin{tabular}{|c|c|c|c|c|c|c|}
\hline \multirow{2}{*}{$\begin{array}{l}\text { Grazing treatment/site } \\
\text { Holistic grazing areas }\end{array}$} & \multicolumn{2}{|c|}{ Number of livestock grazing } & \multicolumn{2}{|c|}{ Number of livestock walking } & \multicolumn{2}{|c|}{ Total number of livestock } \\
\hline & Dry season & Wet season & Dry Season & Wet season & Dry season & Wet season \\
\hline & $2554 \pm 113(74)^{a}$ & $1566 \pm 113(86.2)^{a}$ & $878 \pm 81(26)^{a}$ & $251 \pm 81(14)^{\mathrm{a}}$ & 3432 & 1817 \\
\hline Traditional grazing areas & $7411 \pm 113(57)^{b}$ & $5333 \pm 113(62)^{b}$ & $5684 \pm 81(43)^{b}$ & $3353 \pm 81(38)^{b}$ & 13095 & 8686 \\
\hline LSD & 279 & & 222 & & 1640 & \\
\hline
\end{tabular}

Values with same superscript in the columns are not significantly different at $p<0.05$. Percentages are presented in the parenthesis

Warren et al. 1986; Amiri et al. 2008); hence, livestock are forced to graze on less palatable species which are less nutritious. Overuse of such nutritious plants leads to cessation of growth of certain herbaceous species (Chaichi et al. 2005) such as grass, hence less forage available for the animals. The results suggest that continuous grazing has a potential to negatively affecting livestock productivity through overuse of forage resources, which reduces their availability and quality especially during the critical growth stages. This in turn alters foraging patterns, nutrition, and weight gain of livestock (Hepworth et al. 1991; Ungar and Noy-Meir 1988; Odadi et al. 2009). Overgrazing is known to reduce vegetation cover, soil moisture infiltration, and nutrients in grazing system (No'Am et al. 1994; Amiri et al. 2008), and therefore, it affects the quality of forage obtained by animals when grazing. The quality of forage highly determines the returns from livestock production, and when it is low, livestock production is also expected to be low.

It is evident from the results that animals gain weight faster and produce more milk in areas with high shortduration grazing intensity with long rest periods as compared to those with continuous grazing throughout the year. This is in agreement with Gompert (2010) observation in Nebraska, USA, that holistic grazing increases forage production and enhances grassland health and therefore better animal production per unit area. While the average daily weight gain of sheep was low in HGA, it was high in TGA during the wet season. This could be due to increased moisture content in both HGA and TGA during the wet season which enhances growth of plants, thereby enabling animals to obtain more forage as compared to the dry season. However in HGA, the low weight gain may have been contributed by animal hoof action that resulted in soil compaction during the wet season thereby hindering water infiltration (Mwendera and Saleem 1997; Mapfumo et al. 2000) resulting in poor forage growth. Low infiltration rates result in low plant growth, hence undermining forage productivity. As observed by Faizul et al. (1995) and Amiri et al. (2008), compaction of the soil layer also causes decrease in soil organic material, which hinders growth of vegetation.

Milk yield in goats was lower during the wet season than in the dry season both in HGA and TGA. This may be attributed to the fact that goats are negatively affected by low temperatures during rainy in that they avoid grazing on wet vegetation and shelter from rain; hence, they may not graze adequately in the wet season as compared to the dry season.

\section{Time spent and distance traveled by goats and sheep in holistic and traditional grazing areas}

Goats and sheep spent more time in HGA as compared to TGA. This may be because HGA had more preferred species and more forage due to adequate rest periods, which afforded time and growing conditions for regeneration of defoliated plants (Frank et al. 1998; Teague et al. 2011). In addition, the high amount of animal urine and excrement increases nutrient cycling (Holland et al. 1992; Teague et al. 2011) which enhances plant growth in the HGA. Therefore, livestock and wildlife prefer these areas and would spend more time in them as compared to heavily grazed areas. In TGA, continuous grazing results in overuse of highly preferred palatable plants (Gerrish 2004; Witten et al. 2005; Teague et al. 2011), which are replaced by less preferred unpalatable and less nutritious species (Chaichi et al. 2005; Hosseinzadeh 2006). Animals would therefore not spend much time in TGA and most of the time bypass them in search of areas with more preferred pasture. Animals spent more time during the wet season in both HGA and TGA, and this could be due to moisture availability during the wet season

Table 2 Frequency of wildlife visiting the holistic and traditional grazing areas

\begin{tabular}{|c|c|c|c|c|c|c|}
\hline \multirow{2}{*}{$\begin{array}{l}\text { Grazing treatment/site } \\
\text { Holistic grazing areas }\end{array}$} & \multicolumn{2}{|c|}{ Number of wildlife grazing } & \multicolumn{2}{|c|}{ Number of wildlife walking } & \multicolumn{2}{|c|}{ Total number of wildlife } \\
\hline & Dry season & Wet season & Dry season & Wet season & Dry season & Wet season \\
\hline & $225 \pm 10(74)^{a}$ & $38 \pm 10(79)^{a}$ & $82 \pm 6(26)^{a}$ & $10 \pm 6(21)^{\mathrm{a}}$ & 307 & 48 \\
\hline Traditional grazing areas & $52 \pm 10(32)^{b}$ & $6 \pm 10(35)^{b}$ & $104 \pm 6(68)^{b}$ & $34 \pm 6(85)^{b}$ & 162 & 40 \\
\hline LSD & 24 & & 18 & & 28 & \\
\hline
\end{tabular}

Values with same superscript in the columns are not significantly different at $p<0.05$. Percentages are presented in the parenthesis 

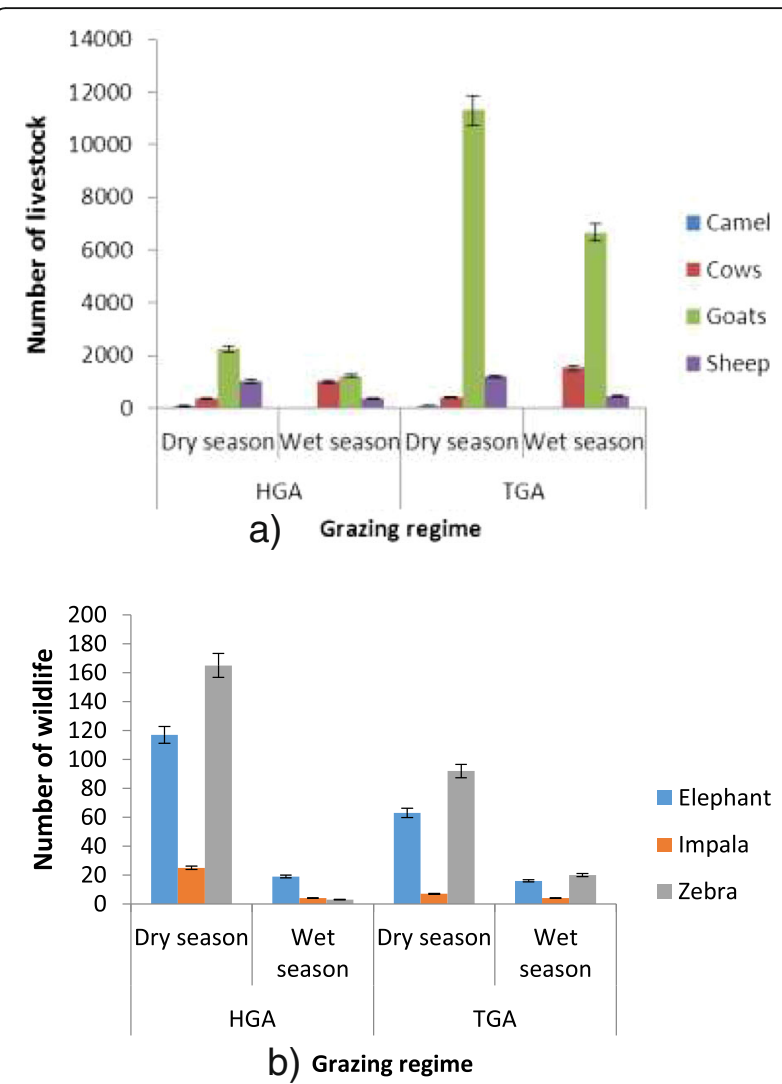

Fig. 8 Livestock (a) and wildlife (b) visiting the holistic and traditional grazing areas

which resulted in increased growth of forage in the sites. However, when there is availability of moisture and increased plant growth in HGA, it leads to even higher plant growth in HGA, hence the higher residence period of grazing animals in them than in TGA.

Goats and sheep in HGA traveled less distance due to availability of adequate forage in these areas as a result of adequate rest periods that allow plant to recover and establish well before they are grazed again. On the other hand, goat and sheep in TGA had to travel longer distance to obtain enough forage for the day due to scarce forage in these areas. Goats are both grazers and browsers, and this explains the shorter distance covered as compared to sheep which are exclusively grazers and therefore have to walk longer distance to select preferred grasses. During the wet season, distance traveled by both goats and sheep was shorter due to availability of more forage occasioned by increased moisture content in the soil both in HGA and TGA.

The grazing movement of livestock in HGA was cyclic as compared to even patterns in the TGA. This is partly due to the fact that when forage is abundant as was the case in HGA, livestock would spend longer time in an area as compared to when forage is scarce as was in the case of TGA. During the dry season, more linear grazing movements were observed because animals would use more or less similar routes from boma outwards to access distant pasture and water points and back. This is expected as pastures and surface water sources around the boma get exhausted during the dry season and therefore herds have to rely on distant sources.

\section{Frequency of livestock and wildlife visits to holistic and traditional grazing areas}

More livestock and wildlife visited HGA than TGA in dry and wet seasons. This could be because forage in HGA was more appealing and preferred by both livestock and wildlife due to the presence of palatable species. The number of livestock and wildlife grazing was higher in HGA as compared to TGA. This could be attributed to these areas having good-quality pasture that was brought by rest periods (Frank et al. 1998) manuring by animals as they graze in HGA (Holland et al. 1992). More animals walked through TGA as they searched for preferred patches with preferred forage species. The number of animals walking was lower during the wet season in TGA, and this could be due to improved forage conditions caused by moisture availability during the wet season. In addition, the frequency of wildlife visits declined in the wet season both in HGA and TGA, and this is attributed to the fact that wildlife only uses these areas during the dry season when pastures in the protected areas are depleted. Less wildlife are therefore expected to visit during the wet season when they have plenty in the parks and reserves. This could also be due to the fact that livestock herds use these areas more during the wet season, which means that the wildlife, especially the zebras would avoid them due to possible conflicts with people. This concurs with Blom et al. (2004), who reported low number of elephants in areas frequented by human and livestock.

Wildlife visits were more in the evening when livestock herds are gone back to the boma both in HGA and TGA. This could be due to the fact that the areas are open and therefore are favored by animals to avoid predation. In addition, elephants and zebras also prefer grazing at night when there is no interference from livestock herds and people. This concurs with de Leeuw et al. (2001) who reported that wildlife avoided areas where livestock herds frequented; hence, they preferred to graze during the night. This is also in agreement with Reid et al. (2008) findings in Mara region, southern Kenya, that due to competition for forage, wildlife tend to avoid areas near pastoral settlements.

\section{Conclusions}

The results from this study show that holistic grazing management can lead to increase in animal weight gain 
and milk yield. They also indicate that livestock and wildlife frequent and spend more time in the holistic grazing areas than in the traditional grazing areas. These findings demonstrate that holistic grazing management has the potential to improve livestock production through increased milk production and faster growth rate of goats and sheep. This is expected to improve food security and income for pastoral households. However, there is a need for long-term studies to replicate this study in different environments to further validate these results.

\section{Acknowledgements}

This work was funded by Princeton University and Mpala Research Center. The authors thank Dr. M. Mkinnard for the invaluable help during the research. We also thank the research assistants Nicholas Lepiyiet and Antony Kamau and community in Koija and IImotiok group ranches for their support during fieldwork

\section{Authors' contributions}

DR developed the concept. PK carried out the field data collection and data analysis and drafted the manuscript. OW, DR, and JTN made comments on the manuscript. All authors read revised and approved the manuscript.

\section{Competing interests}

The authors declare that they have no competing interests.

\section{Author details}

'Faculty of Agriculture, Department of Land Resource Management and Agricultural Technology, University of Nairobi, P.O. Box 29053-00625, Nairobi, Kenya. ${ }^{2}$ Princeton University, Princeton, NJ 08544-2016, USA.

Received: 5 May 2016 Accepted: 14 October 2016

Published online: 29 October 2016

\section{References}

Abel NOJ, Blaikie PM (1989) Land degradation, stocking rates and conservation policies in the communal rangelands of Botswana and Zimbabwe. Land Degrad Dev 1(2):101-123

Amiri F, Ariapour A, Fadai S (2008) Effects of livestock grazing on vegetation composition and soil moisture properties in grazed and non-grazed range site. J Biol Sci 8:1289-1297

Ash J, Stafford-Smith M (1996) Evaluating stocking rate impacts in rangelands: animals don't practice what we preach. Rangel J 18:216-243

Bailey W, Gross E, Laca A, Rittenhouse R, Coughenour B, Swift M, Sims L (1996) Mechanisms that result in large herbivore grazing patterns. J Range Manag 49:386-400

Barnes K, Norton E, Maeno M, Malechek C (2008) Paddock size and stocking density affect spatial heterogeneity of grazing. Rangel Ecol Manag 61:380-388

Blench R, Sommer F (1999) Understanding rangeland biodiversity. Overseas Development Institute, London, $\mathrm{p} 51$

Blom A, Van Zalinge R, Mbea E, Heitkönig I, Prins H (2004) Human impact on wildlife populations within a protected Central African forest. Afr J Ecol 42: 23-31

Brand D, Goetz H (1986) Vegetation enclosures in southwestern North Dakota. J Range Manag 39:434-437

Brooks N, Grist N, Brown K (2009) Development futures in the context of climate change: challenging the present and learning from the past. Dev Policy Rev 27:741-765

Chaichi R, Saravi M, Malekian H (2005) Effects of livestock trampling on soil physical properties and vegetation cover (case study: Lar Rangeland, Iran). Int J Agric Biol 7:904-908

de Leeuw J, Waweru N, Okello O, Maloba M, Nguru P, Said Y, Reid S (2001) Distribution and diversity of wildlife in northern Kenya in relation to livestock and permanent water points. Biol Conserv 100(3):297-306

Dyksterhuis J (1949) Deferred and rotation grazing. Cattleman 35(21):60

Elmore J, Asner P (2006) Effects of grazing intensity on soil carbon stocks following deforestation of a Hawaiian dry tropical forest. Glob Chang Biol 12:1761-1772
Eriksen H, Watson K (2009) The dynamic context of southern African savannas: investigating emerging threats and opportunities to sustainability. Environ Sci Pol 12:5-22

Faizul B, Karlw M, Murray L (1995) Livestock grazing impacts on infiltration rates in a temperate rangeland of Pakistan. J Range Manag 46:367-372

Frank A, McNaughton J, Tracy F (1998) The ecology of the earth's grazing ecosystems. Biol Sci 48:513-521

Galvin A (2009) Transitions: pastoralists living with change. Annu Rev Anthropol 38:185-198

Georgiadis J, Olwero N, Romañach S (2007) Savanna herbivore dynamics in a livestock-dominated landscape: I. Dependence on land use, rainfall, density, and time. Biol Conserv 137(3):461-472

Gerrish J (2004) Management-intensive grazing: the grassroots of grass farming. Green Park Press, Ridgeland

Gompert T (2010) The power of stock density. In: Proceedings of Nebraska Grazing Conference. Kearney.

Hart H, Bissio J, Samuel J, Waggoner W (1993) Grazing systems, pasture size, and cattle grazing behavior, distribution and gains. J Rang Mgt 46(1):81-87, Society for range management

Heath B (2000) Ranching: an economic yardstick. In: Wildlife Conservation by Sustainable Use, vol 12. Springer, Netherlands, pp 21-33

Hepworth W, Test S, Hart H, Waggoner W, Smith A (1991) Grazing systems, stocking rates, and cattle behavior in southeastern Wyoming. J Range Manas 44:258-261

Holland A, Parton J, Detling K, Coppock L (1992) Physiological responses of plant populations to herbivory and other consequences of ecosystem nutrient flow. Am Nat 140:685-706

Hosseinzadeh G (2006) Investigation and comparison of vegetation cover changes and some characteristic of soil in grazed and un-grazed rangeland in Eskelimrood District. Doctoral dissertation, M. Sc. Thesis, Mazandaran University, pp: 117 (In Persian)

Jacobo EJ (2006) Rotational grazing effects on rangeland vegetation at a farm scale. Rangel Ecol Manag 59(3):249-257

Kioko J, Kiringe JW, Seno SO (2012) Impacts of livestock grazing on savanna grassland in Kenya. J Arid Land 4(1):29-35

Mapfumo E, Chanasyk S, Baron S, Naeth A (2000) Grazing impacts on selected soil parameters under short-term forage sequences. J Rang Mgt 53(5):466-470, Society for range management

Mwendera EJ, Saleem MA (1997) Infiltration rates, surface runoff, and soil loss as influenced by grazing pressure in the Ethiopian highlands. Soil use and mgt, 13(1):29-35.

No'Am GS, \& Perevolotsky A. (1994) Has intensive grazing by domestic livestock degraded Mediterranean Basin rangelands?. In Plant-animal interaction in Mediterenian type ecosystems.Series tasks for vegetation science vol 31: (pp. 93-103). Springer Netherlands.

Oba G, Vestaas OR, Stenseth NC (2001) Relationships between biomass and plant species richness in arid-zone grazing lands. J Appl Ecol 38:836-846

O'Connor TG, (1992) Patterns of plant selection by grazing cattle in two savanna grasslands: A plant's eye view. Journal of the Grassland Society of Southern Africa 9 (3):97-104

Odadi O (2010) Competitive and facilitative interactions between cattle and wild ungulates in a semi-arid savanna rangeland in Laikipia, Kenya. PhD Dissertation. Egerton University, Njoro

Odadi O, Karachi K, Abdulrazak A, Young P (2011) African wild ungulates compete with or facilitate cattle depending on season. Science 333(6050):1753-1755

Odadi O, Okeyo-Owuor B, Young P (2009) Behavioural responses of cattle to shared foraging with wild herbivores in an East African rangeland. Appl Anim Behav Sci 116(2):120-125

Ottichilo K, Grunblatt J, Said Y, Wargute W (2000) Wildlife and livestock population trends in the Kenya rangeland. In: Wildlife Conservation by Sustainable Use, vol 12. Springer, Netherlands, pp 203-218

Peterson PR, Gerrish JR (1995) Grazing management affects manure distribution by beef cattle. Proc. Am. Forage Grassland Council, Lexington, pp 170-174

Redden D (2014) Grazing methods effects on forage production, utilization, and animal performance on Nebraska Sandhills meadow. Masters' thesis: UNL

Reid S, Galvin A, Kruska S (2008) Global significance of extensive grazing lands and pastoral societies: an introduction. In Fragmentation in semi-arid and arid landscapes (pp. 1-24) Springer Netherlandsrichness. Science 333(6050): 1750-1753

Ritchie M, Mayemba E, McSherry M, Tear T (2012) Soil carbon dynamics in the Northern Rangelands Trust Member Conservancies, Kenya 
Savory A, Butterfield J (1999) Holistic management: a new framework for decision making. Island press.

Savory A (1978) A holistic approach to ranch management using short duration grazing. In: Proc. of the 1st Intenl Rang Cong Denver, Colorado., pp 555-557

Savory A (1983) The savory grazing method or holistic resource management. Rangl, 5(4):155-159, society for range management

Smet M, Ward D (2006) Soil quality gradients around water-points under different management systems in a semi-arid savanna, South Africa. J Arid Environ 64(2): $251-269$

Snyman A, Du Preez C (2005) Rangeland degradation in a semi-arid South Africa-II: influence on soil quality. J Arid Environ 60(3):483-507

Strauch AM, Kapust R, Jost C (2009) Impact of livestock management on water quality and streambank structure in a semi-arid, African ecosystem. J Arid Environ 73(9):795-803

Teague R, Dowhower L, Baker A, Haile N, DeLaune B, Conover M (2011) Grazing management impacts on vegetation, soil biota and soil chemical, physical and hydrological properties in tall grass prairie. Agric Ecosyst Environ 141(3): $310-322$

Tefera S, Snyman A, Smit N (2007) Rangeland dynamics in southern Ethiopia: (1) Botanical composition of grasses and soil characteristics in relation to landuse and distance from water in semi-arid Borana rangelands. J Environ Manag 85(2):429-442

Thurow L, Blackburn H, Taylor A (1986) Hydrological characteristics of vegetation types as effected by livestock grazing system, Edwards Plateau Texas. J Range Manag 39:505-509

Todd-Brown KEO, Randerson JT, Hopkins F, Arora V, Hajima T, Jones C, Shevliakova E et al (2014) Changes in soil organic carbon storage predicted by Earth system models during the 21st century. Biogeosciences 11(8):2341-2356

Ungar D, Noy-Meir I (1988) Herbage intake in relation to availability and sward structure: grazing processes and optimal foraging. J Appl Ecol 25:1045-1062

Warren D, Thurow L, Blackburn H, Garza E (1986) The influence of livestock trampling under intensive rotation grazing on soil hydrologic characteristics. J Range Manag 39(6):491-495

Willms D, Dormaar F, Schaalje B (1988) Stability of grazed patches on rough fescues grasslands. J Range Manag 41:503-508

Witten Q, Richardson D, Shenker N (2005) A spatial-temporal analysis on pattern formation around water points in a semi-arid rangeland system. J Biol Syst 13:1-23

Wolf K, (2011) Effects of high-density, short-duration planned livestock grazing on soil carbon sequestration potentials in a coastal California mixed grassland (Doctoral dissertation, California Polytechnic State University, San Luis Obispo)

\section{Submit your manuscript to a SpringerOpen ${ }^{\circ}$ journal and benefit from:}

- Convenient online submission

- Rigorous peer review

- Immediate publication on acceptance

- Open access: articles freely available online

- High visibility within the field

- Retaining the copyright to your article 